\title{
JIEM's fourth year: Present status and future avenues
}

Vicenc Fernandez ${ }^{1}$, Maria Albareda-Sambola ${ }^{1}$, Pep Simo ${ }^{1}$, Jose M. Sallan ${ }^{1}$, Mihaela Enache ${ }^{1}$, Josefa Mula ${ }^{2}$, Victoria De la Fuente ${ }^{3}$

${ }^{1}$ Universitat Politècnia de Catalunya, ${ }^{2}$ Universidad Politécnica de Valencia, ${ }^{3}$ Universidad Politécnica de Cartagena (SPAIN)

vicenc.fernandez@upc.edu; maria.albareda@upc.edu; pep.simo@upc.edu; jose.maria.sallan@upc.edu; mihaela.enache@upc.edu;.fmula@,omp.upv.es; marivi.fuente@upct.es

\begin{abstract}
:
This editorial reflects some relevant information about the evolution of JIEM during 2011, together with novel features that have been implemented so far or which are planned to be realized.
\end{abstract}

Keywords: JIEM, editorial

\section{Introduction}

The statistics of the journal show a steady trend in the number of manuscripts received $(\mathrm{N}=109)$ during 2011. During last year, a $32 \%$ of the manuscripts received were accepted, the average reviewing time being 98 days. The number of registered users has a significant increase (513 during 2011), and reached during the previous year a total of 1.367 users. The Journal of Industrial Engineering and Management published 38 papers in 2011, encompassed within 4 issues (two general issues and two special issues, focused on Rethinking Industrial Engineering Higher Education in the European Area (EHEA) and on the best papers of the International Conference on Value Chain Sustainability ICOVACS 2010).

Table 1 illustrates the number of papers published in each field, disclosed by issue. As reflected in this table, Production is still being the most prolific field, as in 2009 and 2010; nevertheless we encourage authors from different areas of industrial 
engineering and industrial management in organizations to submit their original and unpublished manuscripts for evaluation.

\begin{tabular}{|l|r|r|r|r|}
\hline \multicolumn{1}{|c|}{ Field } & $\begin{array}{c}\text { Vol. 4, No. 1 } \\
\text { (Special Issue) }\end{array}$ & Vol. 4, No. 2 & $\begin{array}{c}\text { Vol. 4, No. 3 } \\
\text { (Special Issue) }\end{array}$ & Vol. 4, No. 4 \\
\hline Editorial & 1 & 1 & 10 & 4 \\
\hline PROD & & 6 & & 3 \\
\hline IS & & 3 & & 2 \\
\hline IND & & 1 & & \\
\hline MANAG & & & & \\
\hline FIN & 6 & 1 & $\mathbf{1 0}$ & $\mathbf{9}$ \\
\hline EDUC & $\mathbf{7}$ & $\mathbf{1 2}$ & & \\
\hline Total & & & & \\
\hline
\end{tabular}

Table 1. Papers published in each field and issue (Volume 4) of JIEM

As in the previous years, the complete list of board members is reported in the journal website (Editorial Team). We would also like to thank the editorial board members and the 121 anonymous reviewers for their contribution in reviewing manuscripts submitted to JIEM during 2011.

On one hand, as a novelty with regard to 2010, the papers published in JIEM are now also available in html format. On the other hand, we are pleased to announce readers that we are preparing a special issue that will include the best papers presented at the International Conference on Logistics, Informatics and Service Science (LISS2012), that was held at Beijing Jiaotong University (Beijing, China), July 12-15 where both researchers and industry practitioners could exchange the latest fundamental advances in the state of the art and practice of logistics, informatics, service operations and service science. Moreover, we are negotiating another special issue with the best papers of the International Conference on Low Carbon Transportation and Logistics (LTLGB2012), Green Building, to be held on 12-13 October 2012 where the main theme is "The Integration of technology, policy and management in a low carbon world".

During 2011, editors of JIEM have agreed to a bilateral agreement with the scientific publisher OmniaScience (http://www.omniascience.com) in order to improve the processes of the journal. OmniaScience will allow us to focus the efforts of editors in the academic and scientific processes, leaving less valuable scientific activities such as the layout of articles and issues, to experts designers. Moreover, OmniaScience will help us to index the journal in new international databases and repositories. 
Finally, we invite and encourage authors to send us their conceptual and/or empirical original papers that contribute in advancing knowledge and understanding of phenomena related with all aspects of industrial engineering and industrial management.

Journal of Industrial Engineering and Management, 2012 (www.jiem.org)

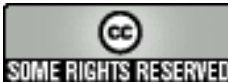

Article's contents are provided on a Attribution-Non Commercial 3.0 Creative commons license. Readers are allowed to copy, distribute and communicate article's contents, provided the author's and Journal of Industrial Engineering and Management's names are included. It must not be used for commercial purposes. To see the complete license contents, please visit http://creativecommons.org/licenses/by-nc/3.0/. 